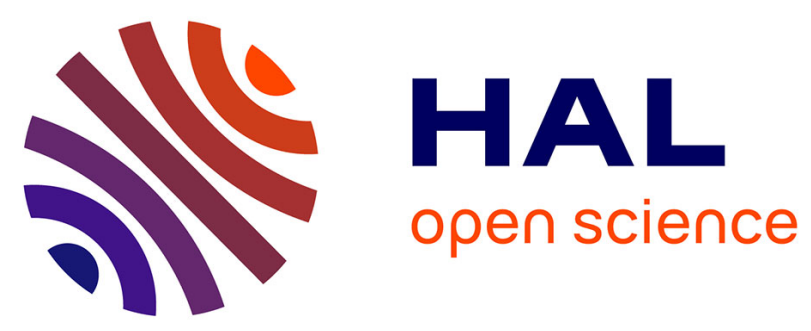

\title{
Detection of Falciparum Malarial Forms in Naturally Infected Anophelines in Cameroon Using a Fluorescent Anti-25-kD Monoclonal Antibody
}

Vincent Robert, Gilbert Le Goff, Julienne Essong, Timoleon Tchuinkam, Brigitte Faas, Jan Peter Verhave

\section{To cite this version:}

Vincent Robert, Gilbert Le Goff, Julienne Essong, Timoleon Tchuinkam, Brigitte Faas, et al.. Detection of Falciparum Malarial Forms in Naturally Infected Anophelines in Cameroon Using a Fluorescent Anti-25-kD Monoclonal Antibody. American Journal of Tropical Medicine and Hygiene, 1995, 52 (4), pp.366-369. 10.4269/ajtmh.1995.52.366 . hal-03363279

\author{
HAL Id: hal-03363279 \\ https://hal.science/hal-03363279
}

Submitted on 3 Oct 2021

HAL is a multi-disciplinary open access archive for the deposit and dissemination of scientific research documents, whether they are published or not. The documents may come from teaching and research institutions in France or abroad, or from public or private research centers.
L'archive ouverte pluridisciplinaire HAL, est destinée au dépôt et à la diffusion de documents scientifiques de niveau recherche, publiés ou non, émanant des établissements d'enseignement et de recherche français ou étrangers, des laboratoires publics ou privés. 


\author{
DETECTION OF FALCIPARUM MALARIAL FORMS IN NATURALLY \\ INFECTED ANOPHELINES IN CAMEROON USING A FLUORESCENT \\ ANTI-25-kD MONOCLONAL ANTIBODY \\ VINCENT/ROBERT, GILBERT/E GOFF, JULIENNE ESSONG, \\ TIMOLEON TCHUINKAM, BRIGITTE FAAS, AND JAN-PETER VERHAVE \\ Departement de Sante, L'Institut Francais de Recherche Scientifique en Cooperation pour le \\ Developpement, Yaounde, Cameroon; Organisation de Coordination pour la lutte contre les \\ grandes Endemies en Afrique Centrale (OCEAC), Yaounde, Cameroon; Institute of Medical \\ Microbiology, University of Nijmegen, Nijmegen, The Netherlands
}

\begin{abstract}
Anopheles gambiae s.s. and An. funestus were sampled in houses located in a Plasmodium falciparumholoendemic site in southern Cameroon. The midguts of female mosquitoes in half-gravid or gravid stages of blood digestion were incubated with a fuorescent monoclonal antibody directed against the $P$. falciparum zygote/ookinete surface protein Pfs25 and examined using a fluorescent light microscope. Malarial forms were detected in $11.6 \%$ of the half-gravid mosquitoes and in $0.0 \%$ of the gravid ones $(P=0.012)$. No difference in infections or the occurrence of malarial forms between An. gambiae and An. funestus was observed. Overall, 127 malarial forms were counted and distributed among round forms, retorts, and ookinetes in $77.2 \%, 9.5 \%$, and $13.4 \%$, respectively. Round forms include macrogametes, activating microgametocytes, and zygotes. The mean number of malarial forms per infected midgut was 2.16 and the maximum number observed was 13 . In four anophelines, round forms, retorts, and ookinetes were simultaneously observed. Sporozoite rates were $5.7 \%$ for An. gambiae and $3.8 \%$ for An. funestus. In the human population, the gametocyte index for $P$. falciparum was $38 \%$ with a mean density of 1.11 gametocytes per microliter of blood. Differences concerning malarial forms in mosquito midguts were observed between houses (range percentage $=4.7-21.3 \%$; mean range of forms per positive anopheline $=1.1-3.1$ ). In each house, relationships existed between infected vectors and the gametocyte reservoir of their inhabitants. The role in transmission of people with very low gametocytemia, approximately one per microliter, as a reservoir of falciparum malaria in highly endemic areas, is emphasized.
\end{abstract}

When ingested by the appropriate mosquito, mature gametocytes of Plasmodium falciparum in the lumen of the mosquito midgut rapidly escape from the erythrocyte to form gametes, then zygotes. Both macrogametes and zygotes appear spherical, approximately $12 \mu \mathrm{m}$ in diameter. The zygote protrudes into a retort, considered by some investigators as an intermediate stage between the zygote and the ookinete. ${ }^{1}$ The elongated ookinetes (approximately $20 \mu \mathrm{m}$ in length) reach the epithelium of the midgut, penetrate this layer, and rest on the external surface, where they round up into young oocysts. ${ }^{2}$ Recently, Beier and others have presented the first field study on ookinetes in anopheline mosquitoes using a classic Giemsa staining for ookinete detection. ${ }^{3}$ In the early stages of parasitic development in the mosquito, namely the female gamete, retort, and ookinete, a $25-\mathrm{kD}$ protein is expressed on the parasite surface. A fluorescent-labeled monoclonal antibody against this neoantigen has been developed and was used in the observation of $P$. falciparum preoocyst stages. Its transmission blocking properties have been evaluated. ${ }^{4}$

The present study examined malarial forms in midguts of anopheline populations from southern Cameroon. The aim was to detect the presence of malarial forms using a fluorescent method and to relate these observations with the anopheline species, the mosquito stages of blood digestion, the presence of sporozoites, and the mean number of gametocytes ingested.

This study is part of a research program on malaria transmission around the major river of southern Cameroon that has been underway since 1989. After preliminary studies along the Sanaga river, the region of Mbebe-Kikot was chosen. Anopheles gambiae s.s. was the only species of the An. gambiae complex observed in this region. ${ }^{5}$ In the Ndonzengue hamlet, the main entomologic parameters were observed during the dry season in 1992, just one year before the survey presented in this report. The biting cycle of $A n$. gambiae and An. funestus was observed (Figure 1); the median was between 2:00 AM and 3:00 AM for An. gambiae and between 3:00 AM and 4:00 AM for An. funestus. Transmission was year-round, with about 200 infected bites/human/year. This transmission was due mainly to An. nili in all seasons, and to An. gambiae in the dry season when breeding sites are provided by the Sanaga river at its lower level; ${ }^{6}$ the role of An. funestus was less important. The rate of in vivo chloroquine drug resistance was $10-21 \%$ at Mbebe-Kikot, mainly at the RI and/or RII levels. ${ }^{7}$

\section{MATERIALS AND METHODS}

Mosquitoes were collected weekly from 7:00 AM to 9:00 AM in bedrooms of four houses in the Ndonzengue hamlet by pyrethrum spray catches. Fifteen collections were done on Wednesdays from January 6 to April 14, 1993 during the dry season.

Anopheles gambiae and An. funestus were placed in an isotherm box at $3-7^{\circ} \mathrm{C}$ and brought by road to the OCEAC laboratory. Samples of the two anopheline species at halfgravid (with the posterior limit of the midgut between abdominal tergits 1 and 2), subgravid (with the midgut not visible at the dorsal side), or gravid blood-feeding stages were selected at each house. Half-gravid mosquitoes had taken their blood meal during the same night, and subgravid or gravid ones had taken theirs during the preceding night.

Mosquito midguts were dissected in saline from noon to 2:00 PM. Midguts were placed in vials with $20 \mu \mathrm{l}$ of $1 \%$ 


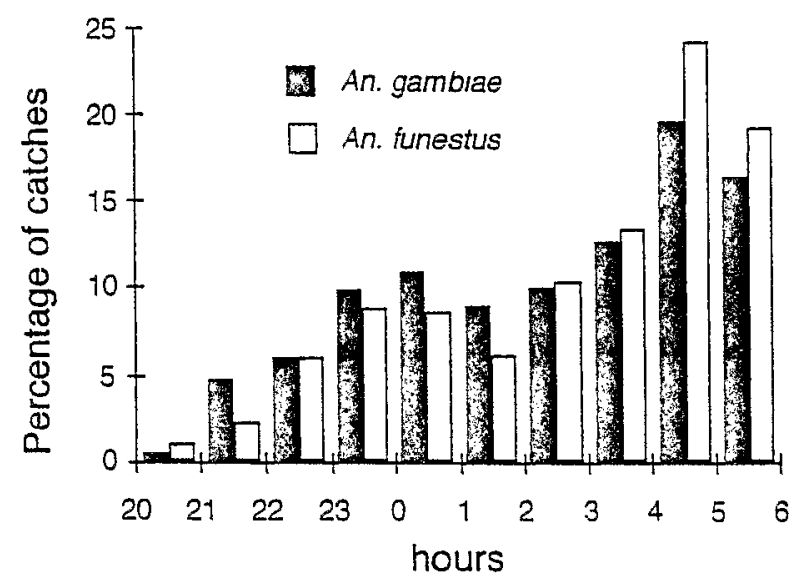

FIGURE 1. Variations in biting rates of Anopheles gambicae and An. fimestus observed with human landing catches in Ndonzengue in southern Cameroon (March-June 1902).

fuorescein isothiocyanate (FITC)-labeled anti-25 kD monoclonal antibody in 0.025\% Evans blue. They were homogenized using a pipette. The suspension containing midgut contents, tissue fragments, and FITC was incubated for 30 min at room temperature, then washed with $1 \mathrm{ml}$ of phosphate-buffered saline (PBS. pH 7.2). After the suspension was centrifuged at $5,000 \times g$ for $2 \mathrm{~min}$, the pellet was homogenized in $10 \mu \mathrm{l}$ of PBS. The mixture was mounted between a microslide and cover glass; desiccation was avoided by sealing the periphery of the cover glass with vaseline. The entire blood mixture was examined at $500 \times$ roil immersion lens) with an incident fuorescent light microscope, a procedure that required approximately $15 \mathrm{~min}$ per slide.

Mosquitoes processed for preoocyst stage detection were also examined microscopically for the presence of sporozoites in the salivary glands. A sample of half-gravid anophelines not processed for detection of malarial forms was anilyzed for the presence of human blood using a dot-enzyme-linked immunosorbent assay in a dipstick, as described by Savage and others: mosquitoes were sampled during five different catches.

Thick blood smears of inhabitants of the four houses where mosquito collecting was conducted were performed on Fehruary 10 and on March 24, 1993. The blood thick smears were immediately dried using a microwave oven." which preserves $P$. fulciparum gametocyte morphology and avoids confusion with other stages of any Plasmodizm species such as $P$. malariae trophozoites (unpublished data). Preparations were stained without fixation with a 4. Giemsa solution for $30 \mathrm{~min}$. Examination at $1.000 \times$ roil immersion lens) for asexual stages of $P$. falciparum and for Plasmodium other than $P$. falciparum was based on 2.000 leukocytes.

TABLE 1

Bloot-feeding status of anophelines collected indors by prethrum sprav atiohs. in Ndonsengue. southern Cumerom iJanuary 1993-April 1993i

\begin{tabular}{lccccc}
\hline Species & Unfed & $\begin{array}{c}\text { Freshly } \\
\text { fed }\end{array}$ & $\begin{array}{c}\text { Half- } \\
\text { grast }\end{array}$ & $\begin{array}{c}\text { Subgrand } \\
\text { and wrand }\end{array}$ & Total \\
\hline An. gambiate & 10 & 1 & 935 & 54 & 1.000 \\
An. innestus & 2 & 1 & 183 & 73 & 259 \\
\hline
\end{tabular}

TABLE 2

Repartition of anophelines with Plasmodium falciparum forms in their midguts. according to their blood-feeding stutus

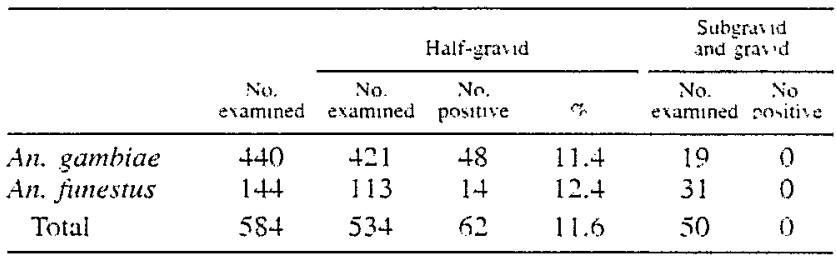

which corresponded to approximately to $0.25 \mu l$ of blood. For gametocyter of $P$. falciparum, examination took 45 min. corresponding to approximately $2.0 \mu \mathrm{l}$ of blood; this was much longer than in routine epidemiologic surveys and served to trace low gametocytemias at the order of $1 / \mu \mathrm{l}$.

Statistical analysis was performed using the chi-square test. when applicable, and the Fisher's exact test.

\section{RESULTS}

Most of the anophelines caught indoors were in the halfgravid stage $193.5 \%$ of An. gambiae and $70.6 \%$ of An. funestus). The difference was significant $\left(\chi^{2}=107.9\right.$. degrees of freedom $[\mathrm{df}]=1: P<0.00011$. corresponding to a higher endophily for An. funestus (Table 1). Preoocyst stages were detected in $11.6 \%$ of 534 half-gravid anophelines examined. No malarial forms were observed in 50 subgravid and gravid anophelines $\left(x^{2}=6.49\right.$, $\mathrm{df}=1 ; P=0.012$ ) (Table 2). There were no differences in the frequency of infections between An. gambite and An. funestus for half-gravid alone: $x^{2}=$ 0.08. df $=1: P=0.77$ ).

Round forms, retorts. and ookinetes were observed at the respective frequencies of $77.2 \%, 9.5 \%$, and $13.4 \%$ (Table 3 ). One round form was observed with two mobile flagella. Round forms or ookinetes were observed alone, but retorts were always associated with another malarial form (Table 4). No differences in the frequency of distinct forms or in number of these forms were observed between An. gambiate and An. funestus. The mean number of malarial forms per infected anopheline was 2.16 (Table 5); the maximum observed value was 13 (Figure 2). The presence of human blood in mosquitoes was verified in $100 \%$ of the tested mosquitoes in $=82$ for An. gambiae and $\mathrm{n}=5$ for 4 . funtstus .

Overall. 28 of $490 \mathrm{An}$. gambiae and six of $157 \mathrm{An}$. funestus showed sporozoites in the salivary glands, yielding sporozoite rates of $5.71 \%$ and $3.82 \%$, respectively $1 x^{2}=$ $0.85 \mathrm{df}=1 ; P=0.351$. The ratios of sporozoite to preoocyst forms were 0.49 (5.7:11.6) for half-gravid An. gambiae and 0.33 (3.8:11.6) for half-gravid An. funestus. There was no

TABLE 3

Anopheline mosquitoes with obsened Plasmodium falciparum in their midgutt.

\begin{tabular}{|c|c|c|c|c|}
\hline & Rrund torm & Retur: & Dokinete & Tratia \\
\hline An. gambiat & $82(77)$ & 111101 & $14(13)$ & $107 / 100$ \\
\hline An finestus & $16(80)$ & $1(5)$ & 31151 & $20,100\}$ \\
\hline Total & $98,77.21$ & 1219.51 & $17(13.4)$ & 1271100.01 \\
\hline
\end{tabular}

* Values are the $110,1 \%$ 
TABLE +

Plasmodium falciparum forms observed in midguts of half-gravid anophelines

\begin{tabular}{|c|c|c|c|c|c|c|c|c|}
\hline & $\begin{array}{c}\text { No. } \\
\text { examined }\end{array}$ & $\begin{array}{l}\text { Round } \\
\text { forms }\end{array}$ & $\begin{array}{c}\text { Round } \\
\text { forms } \\
\text { plus } \\
\text { retorts }\end{array}$ & $\begin{array}{l}\text { Re- } \\
\text { torts }\end{array}$ & $\begin{array}{c}\text { Retorts } \\
\text { plus } \\
\text { ookin- } \\
\text { etes }\end{array}$ & $\begin{array}{c}\text { Ookin- } \\
\text { etes }\end{array}$ & $\begin{array}{l}\text { Round } \\
\text { forms } \\
\text { plus } \\
\text { tetorts } \\
\text { plus } \\
\text { ookin- } \\
\text { etes }\end{array}$ & Total \\
\hline An. gambiae & 421 & 34 & 3 & 0 & 0 & 7 & 4 & 48 \\
\hline An. funestus & 113 & 10 & 1 & 0 & 0 & 3 & 0 & 14 \\
\hline
\end{tabular}

association between the presence of sporozoites in the salivary glands and the detection of malarial forms in the midgut for either An. gambiae or An. funestus ( $P=0.51$ and $P$ $=0.11$, respectively, by Fisher's exact test).

Parasitologic surveys covered all residents of the four houses: 31 residents in February and 35 in March; 30 were present at both surveys. In the three age groups $(0-5$ years of age, 6-19 years of age, and 20 years of age and older), the respective numbers of individuals in each group were 19,15 , and 32 . Results were very constant during the two surveys; thus they were presented together. Plasmodial indices were typical of a highly endermic area (Table 5) for both $P$. falciparum and $P$. malariae (Figure 3). Gametocytes of $P$. falciparum were observed in $38 \%$ of the inhabitants with a geometric mean of $1.11 / \mu 1$ of blood (range $=0.5$ 7). House no. 3 had the three highest values: 1) the proportion of gametocyte carriers of their inhabitants, 2) the percentage of anophelines with malarial forms, and 3) the number of malarial forms per positive anopheline.

\section{DISCESSION}

This is the first study to detect and quantify $P$. falciparum malarial forms in mosquito midguts using an immunofluorescent technique in naturally-infected anopheline vectors. Round forms, retorts, and ookinetes were readily detected and discriminated in midgut preparations from mosquitoes that had fed on humans one night previously.

Observed round forms can be either 1) activated macrogametes, 2) activating microgametocytes, including exfla-

TABLE 5

Plasmodium falciparum forns obsenved in midguts of half-gravid Anopheles gambiae and An. funestus in different houses and data on $\mathrm{P}$. falciparum gametocytemia of inhabitants

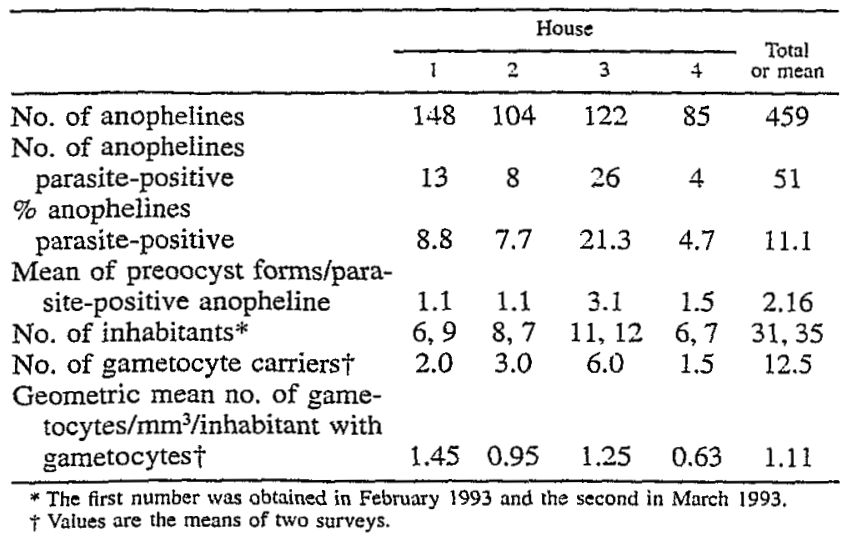

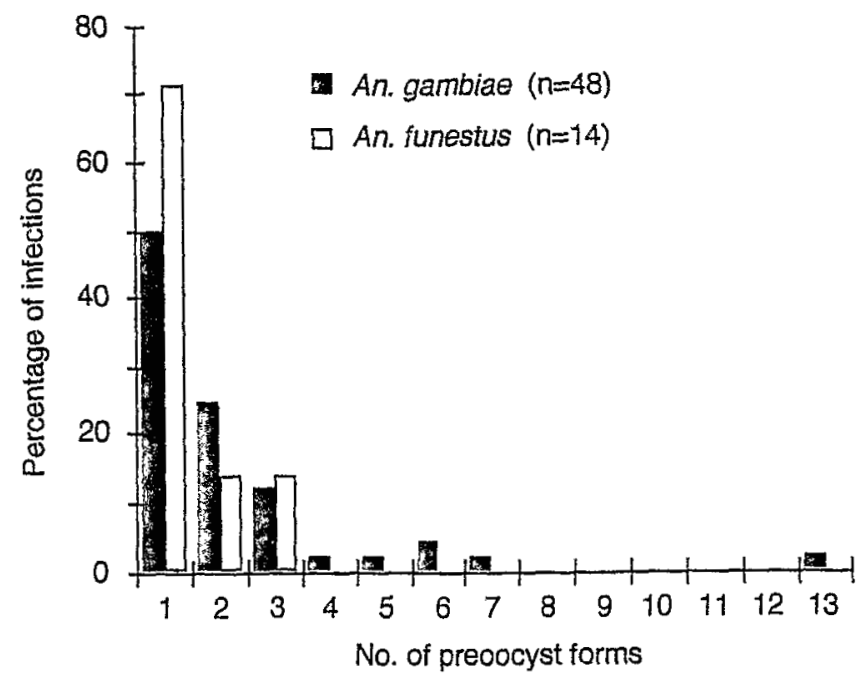

FIGURE 2. Frequency distributions of Plasmodium falcipartm forms detected with an immunofluorescent method in the midguts of Anopheles gambiae and An. funestus inside bouses in Ndonzengue in southern Cameroon.

gellation, and/or 3) zygotes. On the other hand, retorts and ookinetes correspond to a single stage.

The prevalence of malarial forms in anopheline midguts in an area holoendemic for $P$. falcipartum indicated that $11.6 \%$ of human blood meals contained $P$. falciparum gametocytes that had undergone development in anophelines. Retorts and ookinetes were detected in $3.4 \%$ (18 of 534) of half-gravid anophelines and the density of forms per mosquito midgut was 2.16 . These results are similar to those of Beier and others, ${ }^{3}$ who observed $4.4 \%$ of the anophelines with ookinetes and 2.2 ookinetes per mosquito. However, our results and those of Beier and others are difficult to compare because the success of transformation from round forms to ookinetes is unknown. Nevertheless, such low densities of malarial forms associated with such consequential sporozoite rates suggest in the field a high efficiency of the falciparum parasite development within the mosquito. This observation contrasts greatly with experimental infections using cultured $P$. falcipartum gametocytes, in which such low

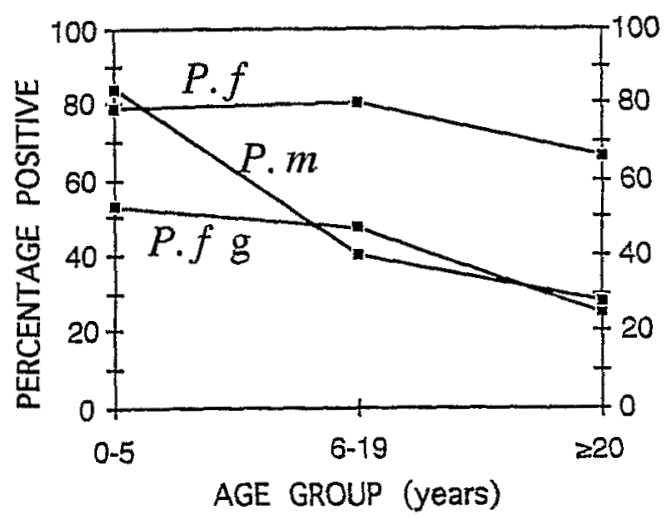

FIGURE 3. Percentage of thick blood smears $(n=66)$ in each age group positive for Plasmodium falciparum $(P . f), P$. malariae $(P . m)$, and gametocytes of $P$. falciparum $(P . f \mathrm{~g})$. 
densities of cokinetes would not be expected to yield sporozoite infections. ${ }^{10}$

Assuming that normal development of malarial forms was stopped after the catches of mosquitoes. our sample of halfgravid anophelines ranged from 2-hr to 12-hr postfeeding. That is to say, the first ookinetes appear between 12 and 15 hr. No forms were observed in mosquito midguts more than 26-hr postfeeding, at a subgravid or gravid stage. On this point, further investigations must be undertaken: our results differ from those of Beier and others, who observed onkinetes 20 - 40-hr postfeeding with highest densities at $31 \mathrm{hr}$. The absence of retorts observed alone is probably due to their short life span: the kinetics of the transformation from round forms to onkinetes needs to be studied further.

The technique described in this study is very useful: the only sophisticated apparatus required is a fluorescent light microscope. Reducing the microscopic examination time for each preparation (15 min in our procedure) would permit an increase number of mosquitoes to be examined.

We attempted to observe the relationships between anopheline infection and gametocyte varriers by house. The results confirm the importance of low gametocytemias of approximately one gametocyte/ $\mu$ l as a natural reservoir of malaria infection." It must be emphasized that such low gametocytemias are normally undetected in routine examinations of thick blond films.

Acknowledgments: We thank Jean-Claude Toto and Roger Beyene for technical assistance, Geert Jan van Gemert. Ton Lensen, and Bert Mulder for training in ummunological techniques, and Will Roeffen and Pieter Beckers for preparing and providing the labeled monoclonal antibody.

Financial anpport: This work was supported by ORSTOM. OCEAC, the French Ministry of Cooperation and Development Convention 91013800 , the French Ministry of Research and Space Contract 92.L.0051, and the European Economic Community STD-3 Project PL910240.

Authors' addreses: Vincent Robert, Malaria Laboratory. ORSTOM. PO Box 1385. Dakar. Senegal. Gilbert Le Goff. Julienne Essong. and Timoleon Tchuinkam. Department of Medical Entomology, Antenne ORSTOM of OCEAC. PO Box 288. Yaounde. Cumeroon. Brigitte Fias and Jan-Peter Verhave, Institute of Medical Microbi- ology, Department of Parasitology. University of Nijmegen, Geert Grooteplein Zuid 24. $6500 \mathrm{HB}$ Nijmegen, The Netherlands.

Reprint requests: Vincent Robert. Mataria Laboratory, ORSTOM. PO Box 1386. Dakar. Senegal.

\section{REFERENCES}

1. Meis JFGM. Wismans PGP. Jap PHK. Lensen AHW. Ponnudurai T. 1992. A scanning electron microscopic study of the sporogonic development of Plasmotium falciparum in tropheles stephensi. teta Trop 50: 227-236.

2. Garnham PCC. 1988. Malaria parasites of man: life-cyeles and morphology. Wernsdorfer WH, McGregor I, ed. Malaria: Princtples and Practice of Mulariolugy, Volume 1. Edinhurgh: Churchill Livingstone, 6l-9t.

3. Beier JC, Copeland RS, MItalib R. Vaughan JA. 1992. Ookinete rates in Afrotropical anopheline mosquitoes as a measure of human malaria infectiousness. Am J Trop Med Hyg $17: 41-$ $+6$.

4. Lensen AHW van Gemert GJA. Bolmer MG, Meis JFGM, Kaslow D, Meuwissen JHETh. Ponnudurai T. 1992. Transmission blocking antibody of the Plasmodium falciparum zygote/ookinete surface protein Pfs25 also influences sporozoite development. Parasite Immunol $14: 471 \ldots 79$

5. Robert V, Petrarca V, Le Goff G. Manga L. 1993. Quelques donnees cytogenetiques sur le complexe thopheles gambiae au Sud-Cameroun. Bull Liais Doc OCEAC 26: 99-101.

6. Carnevale P, Le Goff G. Toto JC, Rohert V, 1092. Anopheles nili as the main vector of human malaria in villages of southern Cameroon. Hed let Enomol 6: 135-138.

7. Louis JP, Hengy G, Louis FJ, Gazin P, Jambou R. Gardon J. Fadat G. Trebucq A, 1992. Proposals for a new therapeutic strategy for simple Plasmodium falctparum malarıa artack in Cameroon. Trop . Hed Parasitol t3: 118-120.

8. Savage HM. Duncan JF Roberts DR. Sholdt LL. 1991. A dipstick ELISA for rapid detection of human blood meals in mosquitoes. J Am hosa Control Assoc $: 16-23$.

9. Chevalier B, Cavallo JD. Baudet JM. Samson T, Gros P. Crenn Y. Meyran M. 1992. Diagnostic rapide du paludisme: le four a micro-ondes. Bull Soc Pathol Exot 85: $223-225$.

10. Vaughan JA. Noden BH. Beier JC, 1992. Population dynamics of Plasmodium falciparum sporogony in laboratory-infected Anopheles gambite. J Parasitol $8: 716-724$.

11. Boudin C, Olivier M, Molez JF, Ambroise-Thomas P, 1903. Malaria infectivity of an African populanon 10 mosquitoes in the Bobn-Dioulasso area. Burkina Faso. Am J Trop . Med Hyg +8 : $700-706$. 
The American Journal of

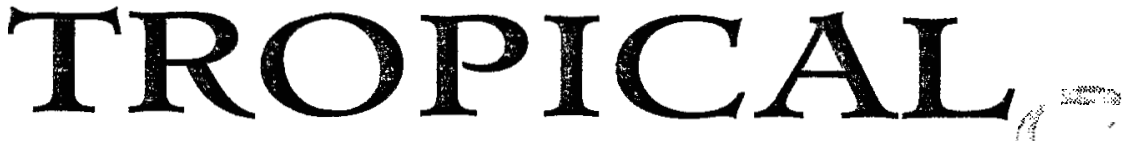

MEDICINE

HYGIENE

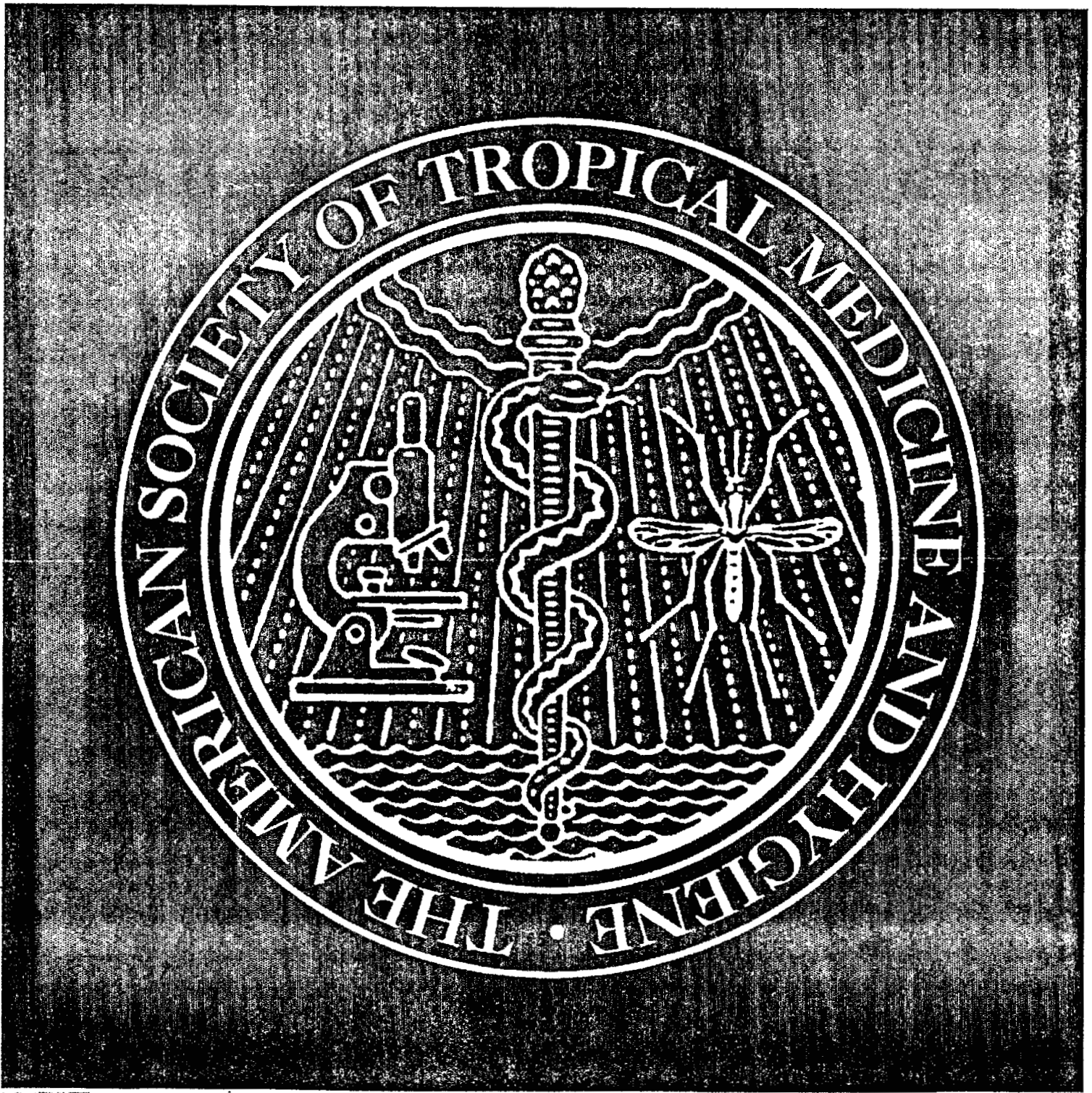

PH 86

OFFICIAL ORGAN OF

SANTÉ ISSN 0002-5637 MODAC: DAFAF 